\title{
Preparation of Carbide-Type, Advanced LMFBR Fuel Pellets for Irradiation Testing
}




\title{
Preparation of Carbide-Type, Advanced LMFBR Fuel Pellets for Irradiation Testing
}

\author{
R. L. Gutierrez \\ R. J. Herbst
}
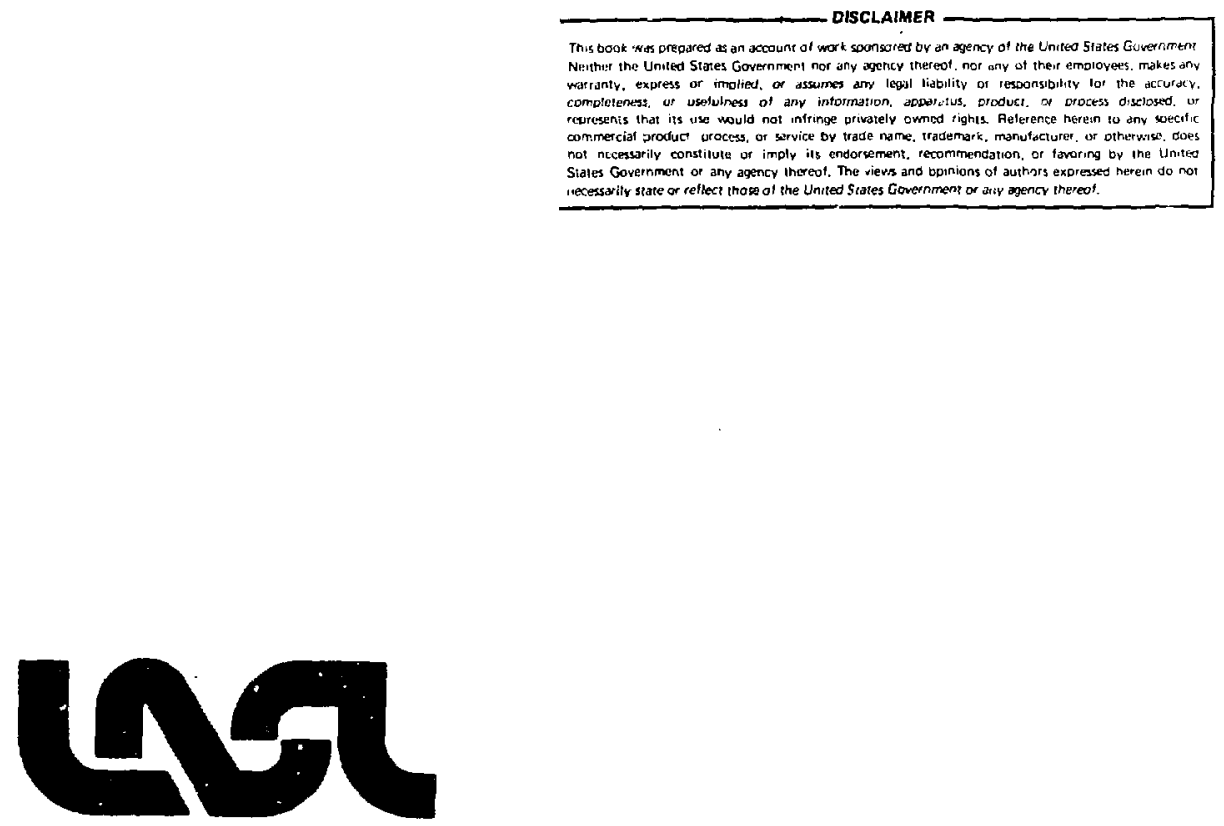


\title{
PREPARATION OF CARBIDE-TYPE, ADV ANCED LMFBR FUEL PELLETS FOR IRRADIATION TESTING
}

by

\author{
R. L. Gutierrez and R. J. Herbst
}

\begin{abstract}
A carbothermic reduction process was established to fabricate single- and two-phase uranium-plutonium carbide fuel on a production basis. Sintering temperatures of 1550 and $1800^{\circ} \mathrm{C}$ were used to prepare fuel densities of 98,87 , and $81 \%$ of theoretical.
\end{abstract}

\section{INTRODUCTION}

Uranium-plutonium carbide fuel is being considered as a prime candidate of the Advanced Fuels Program for the fast breeder reactor (FBR). The carbide fuel has higher metal density, thermal conductivity, and superior breeding ratio properties than conventional uranium-plutonium oxide fuel. Irradiation experirnents were designed to investigate chemical and physical interactions between the carbide fuel and the cladding and thermal bonding medium, the fuel swelling, the fission gas release, and the migration of fuel material and fission products as a function of burnup and irradiation conditions. For this reason, carbide fuel of different densities and phase composition is being fabricated for tests being conducted in the Energy Breeder Reactor II (EBR-II) and Fast Flux Test Facility (FFTF) reactors.

\section{FUEL COMPOSITION}

\section{A. Monocarbide-Sesquicarbide Phase Composi- tion}

Advanced FBR fuel pellets are fabricated by using the carbothermic reduction process. In recent years, the composition of the fuel is of a mixed uraniumplutonium carbide of two types. The first type is essentially single-phase $(\mathrm{U}, \mathrm{Pu}) \mathrm{C}$ and the second type is two-phase $(\mathrm{U}, \mathrm{Pu}) \mathrm{C}+10$ vol\% $\mathrm{M}_{2} \mathrm{C}_{\mathrm{s}}$. The singlephase fuel was fabricated at the Los Alamos Scientific Laboratory (LASL) only as $87 \%$ of theoretical density (T.D.) using the carbothermic reduction method, whereas the two-phase fuel was fabricated as 98,87 , and $81 \%$ T.D. pellets. The single-phase fuel fabricated at LASL has $\geqq 93 \%$ T.D. using the arc-melting method ${ }^{1}$ and $\mathrm{Fass}^{2}$ fabricated a single-phase fuel of $93 \%$ T.D. using the carbothermic reduction methód.

\section{B. Two-Phase Fuel}

The two-phase composition fuel is the predominant fuel fabricated at LASL. This amounts to approximately $95 \%$ of the carbide fuel fabricated during the past 6 years. Figure 1 illustrates the basic carbothermic reduction process used to fabricate two-phase carbide fuel through sampling and inspection. The phase composition is controlled by the amount of carbon (graphite) added to the starting 


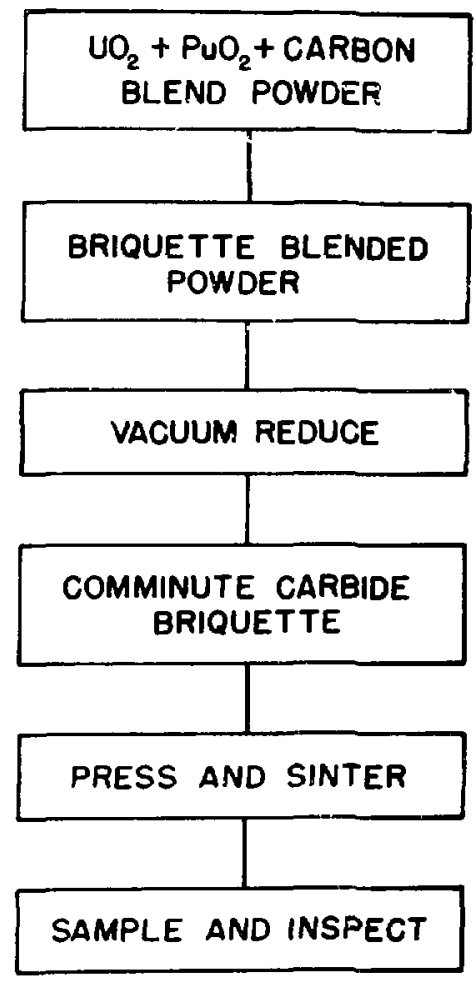

Fig. 1 .

Carbothermic reduction process.

oxides. We hypothesized and subsequently corroborated, by both basic studies and production experience, that the hyperstoichiometric oxygen associated with the uranium and plutonium oxides reacted at relatively low temperatures to form $\mathrm{CO}_{2}$. The remaining stoichiometric oxide reacted with carbon at higher temperatures to form $\mathrm{CO}$. An equation ${ }^{3}$ for forming a mixed (U,Pu)-carbide was assumed as

$$
\begin{aligned}
&(1-i) U_{2+x}+a P u O_{2 \pm y} \\
&+ {\left[3+n+\frac{x}{2}(1-a) \pm \frac{y}{2} a\right] c+} \\
&(1-2 n)\left(U_{1-a}, P u_{a}\right) C \\
&+ n\left(U_{1-a}, P u_{a}\right)_{2} C_{3}+2 C O \\
&+ {\left[\frac{x}{2}(1-a) \pm \frac{y}{2}\right] C_{2} . }
\end{aligned}
$$

When we compounded the starting materials according to this equation, the production and control of hyperstoichiometric compositions containing $10 \pm$ $5 \mathrm{vol} \%$ of sesquicarbide were satisfactory (Fig. 2).

VDLUME \% 5ESEUICARBIDE

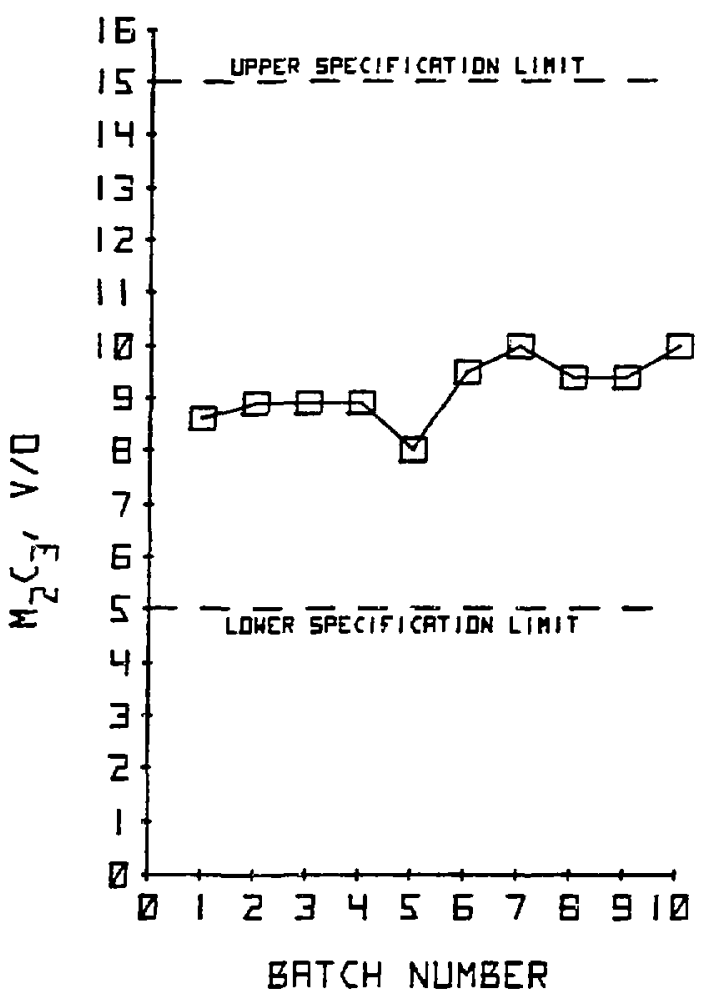

Fig. 2.

Compositional control in the preparation of (U,Pu)-carbide.

The 98,87 , and $81 \%$ two-phase fuel densities were prepared by the process parameters illustrated in Figs. 3, 4, and 5. For the three densities, the parameters are identical through the vacuum reduction step. It is in the comminution (grinding) and sintering steps where the process parameters are varied to obtain the particular density desired. Of the three prepared fuel densities, the $98 \%$ dense twophase fuel is the easiest to fabricate on a production basis. To achieve high density, a small amount of nickel is used as a sintering aid. This imparts better 


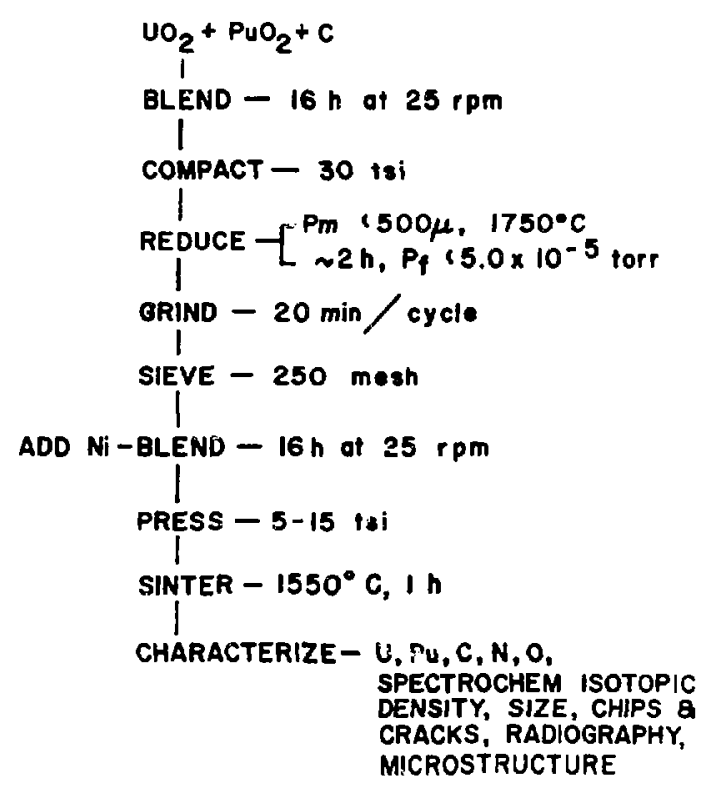

Fig. 3.

Process parameters for the preparation of pelleted, high-density, two-phase (U,Pu)-carbide.

control on the density and allows the use of a shorter sintering cycle. Typically, the $98 \%$ dense fuel does not vary more than $1 \%$ from one batch to another. The $81 \%$ dense fuel exhibits a $2 \%$ density variation for several batches of fuel. The $87 \%$ dense fuel often shows a $4 \%$ density variation over several batches of fuel. Figures 6,7 , and 8 show the density variation per 10 batches of 98,87 , and $81 \%$ dense fuel. The rejection rate for fuel not meeting the density specification is $<1 \%$. However, better control of the $87 \%$ dense fuel process is being sought so that the density will not vary more than $2 \%$ on a batch-tobatch basis.

\section{Single-Phase Fuel}

Fabrication of a single-phase $87 \%$ dense fuel is nearly identical to two-phase fuel. The only additional step added to the carbothermic reduction process is hydrogen treatment. This stage of the operation occurs between the comminution and pressing steps (Fig. 9). The process involves

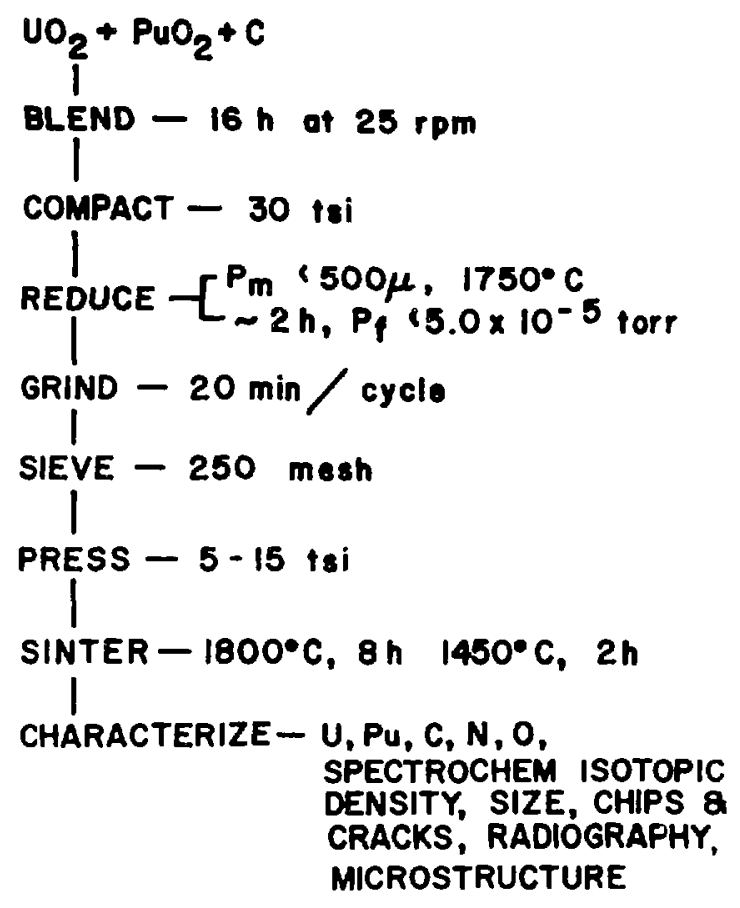

Fig. 4.

Process parameters for the preparation of pelleted, $87 \%$ dense, two-phase (U,Pu)-carbide.

spreading the carbide powder in long thin trays that are inserted into a horizontal furnace. The furnace is heated to $900^{\circ} \mathrm{C}$ and purified hydrogen gas flows through the furnace for 0.35 hours/g of carbide powder. The hydrogen reacts with carbon as

$$
2 \mathrm{H}_{2}+\mathrm{M}_{2} \mathrm{C}_{3} \longrightarrow 2 \mathrm{MC}+\mathrm{CH}_{4} \uparrow
$$

The hyperstoichiometric system is then reduced to a single-phase state. When this method was used, fuel pellets were fabricated that were essentially singlephase material. Both chemical and microstructural analysis data verified that the fuel contained $<0.2$ vol\% of $\mathrm{M}_{2} \mathrm{C}_{3}$ and there was no evidence of free metal. At the end of the hydrogen treatment step, the carbide powder is very reactive and care must be taken not to expose the carbide powder to oxygen or moisture levels $>10 \mathrm{ppm}$. The reactive condition of the carbide powder, the additional time for hydrogen treatment, and the additional safety 


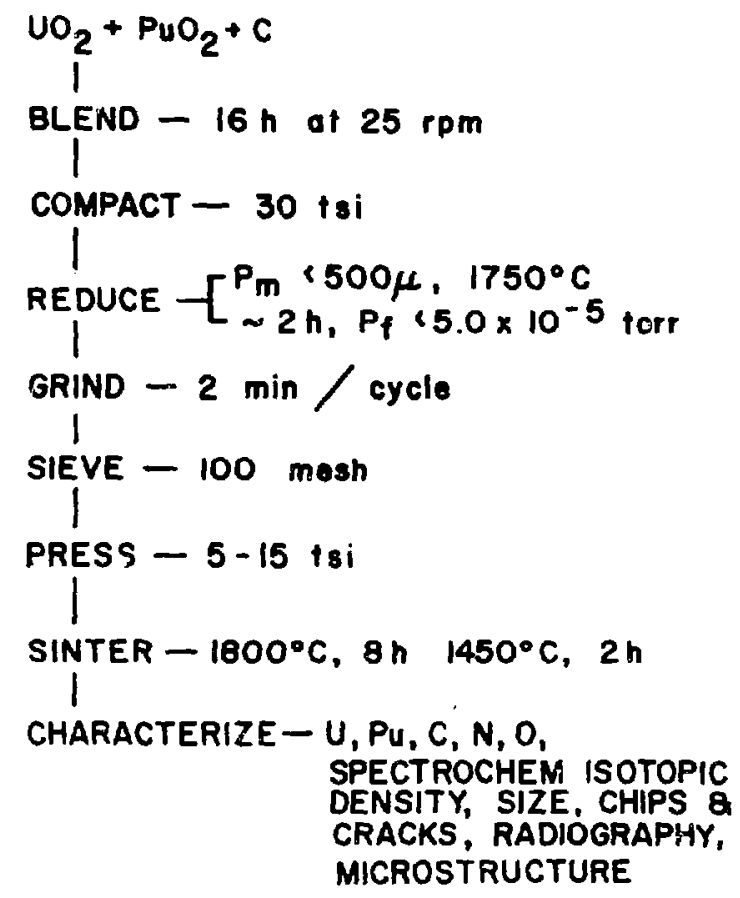

Fig. 5.

Process parameters for the preparation of pelleted, $81 \%$ dense, two-phase $(U, P u)$-carbide.

measures required when working with hydrogen make the fabrication of single-phase fuel more difficult than the two-phase fuel.

\section{DETERMINATION OF SESQUICARBIDE CONTENT}

Determination of the amount of $\mathrm{M}_{2} \mathrm{C}_{8}$ in a hyperstoichiometric fucl was challenging because of the difficult selection of an analytical technique to determine the amount of $\mathrm{M}_{2} \mathrm{C}_{3}$. The methods pur sued were the use of chemical analysis data for equivalent carbon $(\mathrm{C}+\mathrm{N}+\mathrm{O})$ and quantitative metallography (QM). In equivalent carbon analysis, oxygen and nitrogen are assumed atomically equivalent to carbon and can be substituted for carbon in the carbide crystal lattice structure.

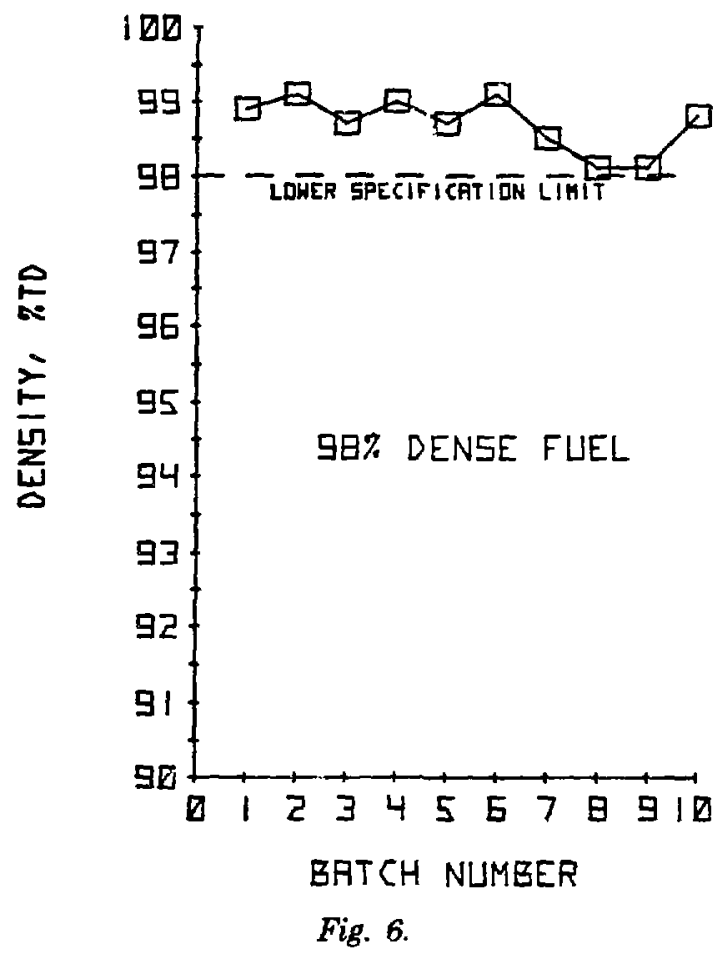

Density control during the preparation of pelleted, high-density (U,Pu)-carbide.

Measurements of the $\mathrm{M}_{2} \mathrm{C}_{8}$ volume proportion by these two methods correlated well for 98:- dense fuel. When $Q M$ is used, the $\mathrm{M}_{2} \mathrm{C}_{2}$ appears as large grains of uniform size in the $98 \%$ dense fuel, but in the 87 and $81 \%$ dense fuel, the $\mathrm{M}_{2} \mathrm{C}_{s}$ tends to be irregular in grain size throughout the pellet. QM tended to give $\mathrm{M}_{2} \mathrm{C}_{3}$ values that were 1 to 2 vol\% lower than those values obtained by carbon equivalent analysis for the two low-density fuels. The lower QM values for the low-density fuel may be due to the porosity of the material and the smaller grain size of $\mathrm{M}_{2} \mathrm{C}_{3}$ as opposed to the high-density material. This is illustrated in Fig. 10 by photomicrographs of sintered two-phase fuel pellets. Also shown is the microstructure of a single-phase fuel pellet. Because of this, the equivalent carbon method is being used to certify the amount of $\mathrm{M}_{2} \mathrm{C}_{\mathrm{B}}$ 


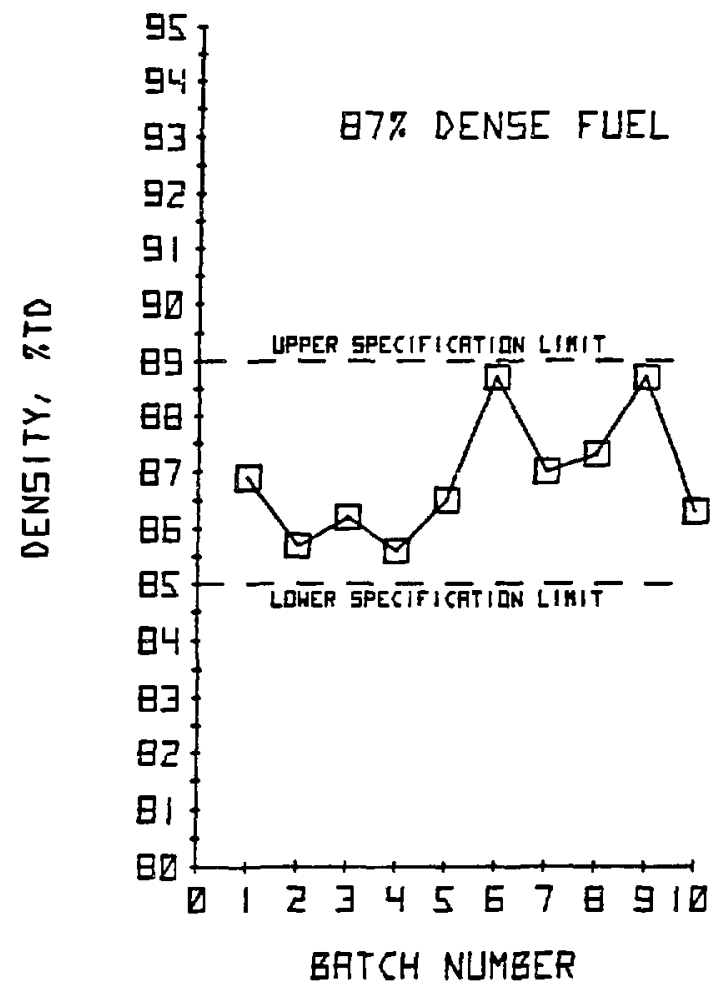

Fig. 7.

Density control during the preparation of polleted, $87 \%$ dense (U,Pu)-carbide.

specified to be in the hyperstoichiometric fuel and QM is used as a visual crosscheck.

Analytical data from many experimental batches were plotted on a graph showing $\mathbf{M}_{2} \mathrm{C}_{3}$ vol\% v8 carbon equivalent. These data correlated well with the line generated by assuming a stoichiometric reaction between the metals and the equivalent carbon to produce $\mathrm{MC}+\mathrm{M}_{2} \mathrm{C}_{2}$. Figure 11 shows this line curve and the one generated for $U_{3} C_{2}$ (the insulator pellets). Both of these curves are standard for determining the amount of second-phase material in fuel or insulator pellets.

\section{FACILITIES AND PROCESS EQUIP- MENT}

\section{A. Glovebox Operation and Atmosphere}

Processing is done in hermetically sealed gloveboxes that are operated at a small negative

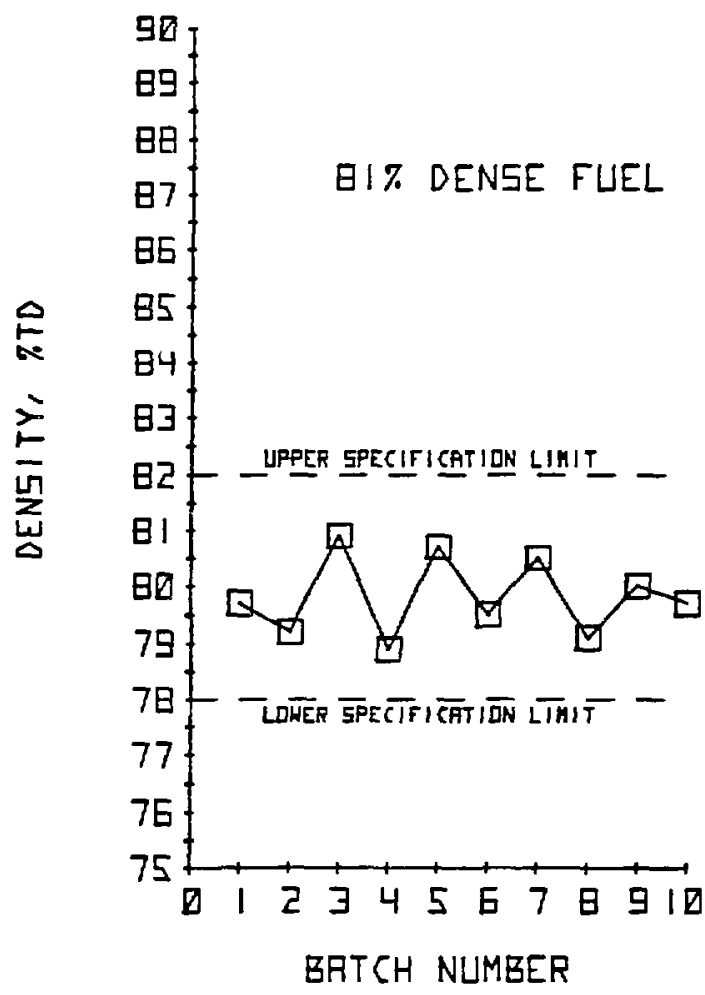

Fig. 8.

Density control during the preparation of pe:leted, $81 \%$ dense (U,Pu)-carbide.

pressure compared to the room pressure. This negative pressure range is $0.25-0.50$ in. of $\mathrm{H}_{2} \mathrm{O}$. The oxide blend is processed in a dry air atmosphere containing $15-30 \mathrm{ppm}$ of moisture. After the carbothermic reduction step, the carbide material is processed in an inert atmosphere (argon) containing $\leqq 10 \mathrm{ppm}$ each for oxygen, nitrogen, and moisture. The inert atmosphere is maintained by a DRI-TRAIN system, which continuously recirculates the inert gas through purifier beds that physically remove the moisture and chemically remove the oxygen and nitrogen from the gas.

\section{B. Process Equipment}

Fuel fabrication initially was limited to a $500-\mathrm{g}$ batch size. This limitation was due primarily to 


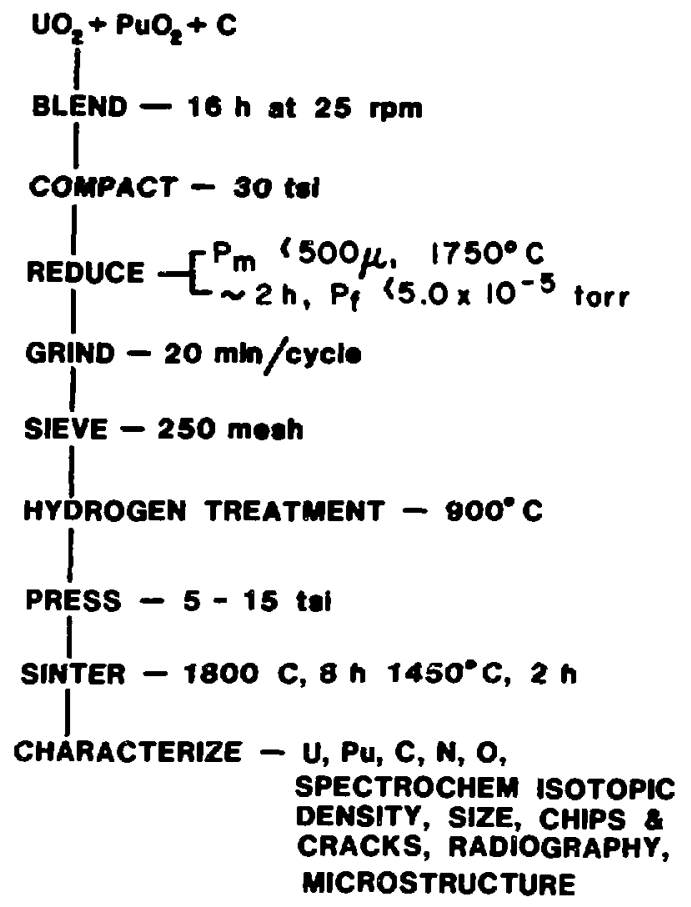

Fig. 9.

Operations and process parameters for the preparation of pelleted, $87 \%$ dense, singlephase (U,Pu)-carbide.

having a 3-in.-diam heat zone furnace for the carbothermic reduction and sintering steps. We also used a Spex mill for comminution of the briquettes, but no automatic pressing equipment. However, new facilities and equipment are now in use. The new production line has larger furnases, a jaw crusher and vibratory mill for comminution, and an automatic press that ircrease the batch size to 3000 g. Figure 12 illustrates the parameters now being used with the new equipment to fabricate $98 \%$ dense two-phase fuel pellets. This line has a $300-\mathrm{kg} / \mathrm{year}$ capacity of processed material. A second production line, with a $500-\mathrm{kg} /$ year capacity, will soon be operational.

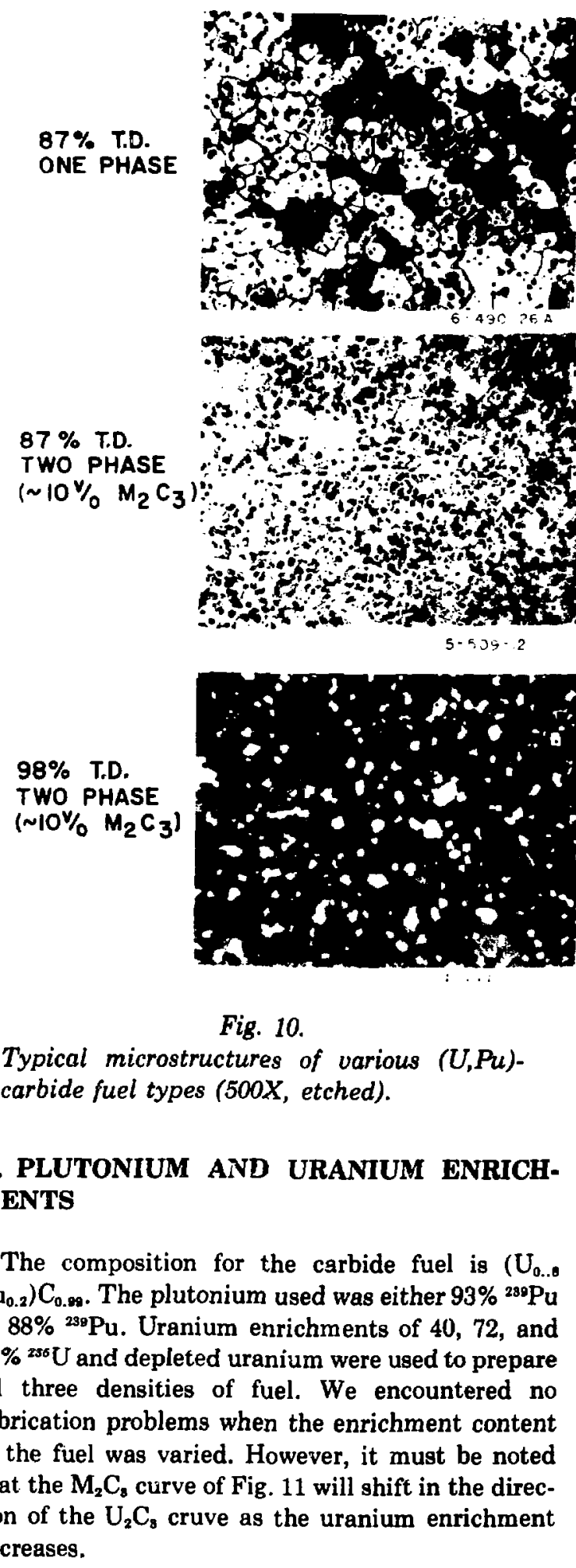




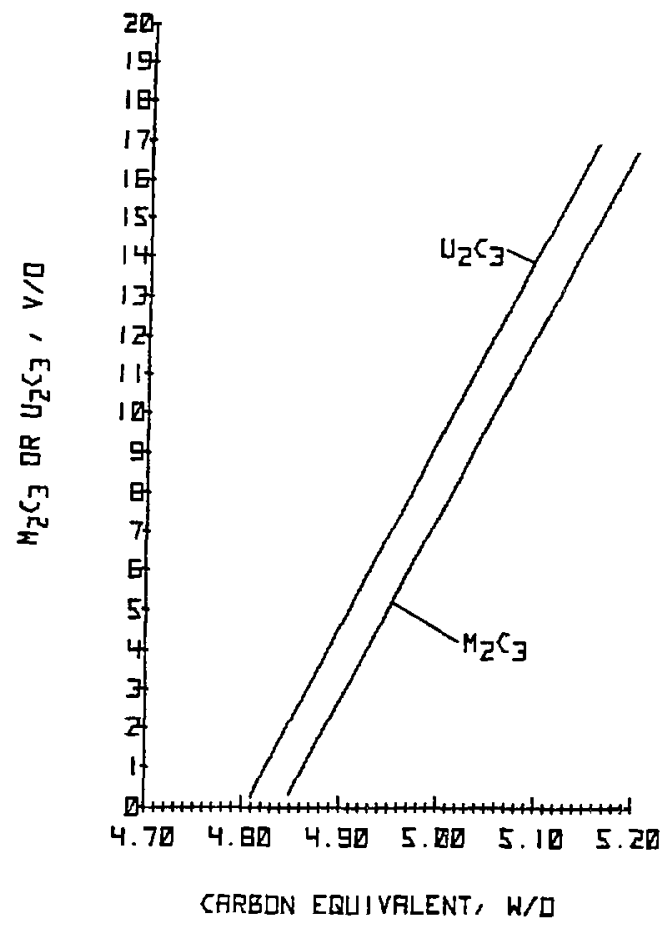

Fig. 11.

Sesquicarbide content of $U$-carbide and $\left(U, P_{L}\right)$-carbide inferred from carbon equivalent analysis.

\section{CONCLUSION}

A production process for fabricating 98,87 , and $81 \%$ dense $(\mathrm{U}, \mathrm{Pu}) \mathrm{C}+10 \pm 5 \mathrm{vol} \% \mathrm{M}_{2} \mathrm{C}_{\mathrm{g}}$ fuel was established using the carbothermic reduction method. For the single-phase fuel, the hydrogen reduction step must be improved so that processing kilogram quantities of carbide powder does not limit the rate of the total process. However, no development effort has been made in this direction because reactor experiment designers have found that the two-phase fuel exhibits less swelling than the single-phase fuel during in-reactor performance. This finding has precluded the use of single-phase fuel for current and planned irradiation tests.

Because of the equipment available at the time, the oxide blend batch size was limited to $500 \mathrm{~g}$. New facilities and equipment now in operation allow $3000-\mathrm{g}$ batches with a potential production rate of

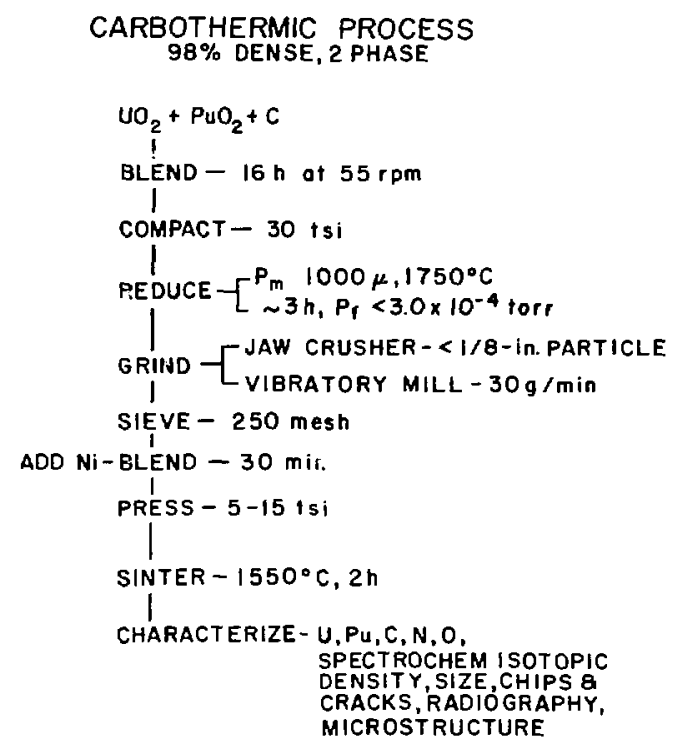

Fig. 12.

Operations and process parameters used in the current process for the production of pelleted high-density $(U, P u)$-carbide fual for irradiation testing.

$300 \mathrm{~kg}$ of two-phase carbide fuel per year. A second production line will soon be in operation and this line will process $500 \mathrm{~kg}$ of two-phase carbide fuel per year.

\section{REFERENCES}

1. R. D. Baker, Comp., "Advanced Fast Reactor Fuels Program, Second Annucl Report, July 1, 1975-Septem ber 20, 1976," Los Alamos Scienticfic Laboratory report LA-7570-PR (December 1978), pp. 17-21.

2. E. Fass, "Experiment Description and Hazards Analysis for Fuel Rods UNC 241 through UNC 259 Nineteen Experimental (U,Pu)C - Fueled EBR-II Rods," AEC Research and Development report GU-5280 (December 1971). 
3. R. J. Herbst, K. W. R. Johnson, and J. L. Green, "(U,Pu)-Carbide Fuel Fabrication Process Variables," paper presented at the information meeting of the Fuel Element Development Programs, Richland, Washington, May 2-4, 1978. 